\title{
Adenosine deaminase level in pleural fluid and the diagnosis of tuberculous pleural effusion
}

Hong Kong Med J 2018;24:317

DOI: $10.12809 / \mathrm{hkmj} 187336$

To the Editor-Tuberculous pleural effusion (TBPE) is often elusive to diagnostic investigations and clinicians often use adenosine deaminase level (ADA) as a surrogate marker to justify anti-tuberculosis (TB) treatment. In the February 2018 issue of the Hong Kong Medical Journal, Chang et $\mathrm{al}^{1}$ made an important contribution by defining a lower cut-off value to increase its sensitivity. The authors rightly pointed out the limitations of this marker and added an upper cut-off value of $100 \mathrm{U} / \mathrm{L}$ to enhance its efficacy. While appreciating the high value of this contribution, may I suggest the following caveats.

I have noticed that ADA was not tested in pleural fluid in some non-endemic areas where the prevalence of TB was low. The predictive value of this test is dependent on the prevalence of TB among the population. If $\mathrm{TB}$ prevalence is high, the positive predictive value will be higher but the negative predictive value will be lower. If TB prevalence is low, the effect will be reversed, the positive predictive value will be lower, and the negative predictive value will be higher. ${ }^{2}$ As the prevalence of TB varies from place to place and from time to time for the same place, the predictive values of the ADA test might need to be adjusted accordingly.

Secondly, among the most recent four cases of TBPE that I have encountered, one patient presented with an ADA of $102 \mathrm{U} / \mathrm{L}$. His pleural biopsy was TB positive. If we had adopted the upper cut-off value of $100 \mathrm{U} / \mathrm{L}$ as advocated by Chang et al, ${ }^{1}$ we would have excluded this case.

\section{Declaration}

The author has no conflicts of interest to disclose. The author had full access to the data, contributed to the study, approved the final version for publication, and take responsibility for its accuracy and integrity.

John SM Leung *, FCSHK, FHKAM (Surgery)

Cardiothoracic Surgery, St Paul's Hospital, Causeway Bay, Hong Kong

*Corresponding author: leungsiumanjohn@yahoo.com.hk

\section{References}

1. Chang $\mathrm{KC}$, Chan MC, Leung WM, et al. Optimising the utility of pleural fluid adenosine deaminase for the diagnosis of adult tuberculous pleural effusion in Hong Kong. Hong Kong Med J 2018;24:38-47.

2. Pennsylvania State University. Eberly College of Science, STAT 507, Chapter 10.3. Sensitivity, specificity, positive predictive value and negative predictive value. Available from: https://webaccess.psu.edu/?cosign-onlinecourses. science.psu.edu\&https://onlinecourses.science.psu.edu/ stat507/node/71. Accessed 28 Feb 2018. 